\title{
Psychiatrists' awareness of partial and nonadherence to antipsychotic medication in schizophrenia: results from an Asia-Pacific survey
}

This article was published in the following Dove Press journal:

Neuropsychiatric Disease and Treatment

9 August 2013

Number of times this article has been viewed

Jose Manuel Olivares'

Manickam Thirunavukarasu ${ }^{2}$

Jayashri Kulkarni ${ }^{3}$

Hong Yan Zhang ${ }^{4}$

Mingyuan Zhang ${ }^{5}$

Fan Zhang ${ }^{6}$

'Department of Psychiatry, Hospital Meixoeiro, Complejo Hospitalario Universitario de Vigo, Vigo, Spain;

${ }^{2}$ Department of Psychiatry, SRM

Medical College Hospital and

Research Center, Tamil Nadu, India;

${ }^{3}$ Department of Psychiatry, Monash

University and the Alfred Hospital,

Prahran, Vic, Australia; ${ }^{4}$ Department of

Psychiatry, Peking University Institute

of Mental Health, Beijing, People's

Republic of China; ${ }^{5}$ Department of

Psychiatry, Shanghai Mental Health

Center, Shanghai, People's Republic of

China; 'Medical Affairs, Xian Janssen

Pharmaceutical, Beijing, People's

Republic of China
Correspondence: José Manuel Olivares Department of Psychiatry, Hospital Meixoeiro, Complejo Hospitalario Universitario de Vigo, Avda. do

Meixoeiro, s/n 362I4-Vigo

(Pontevedra), Spain

$\mathrm{Tel}+349868 \mathrm{I} \mathrm{IIII}$

Fax +3498681 II 50

Email jose.manuel.olivares@gmail.com
Background: Nonadherence is a well-known problem among schizophrenia patients, among whom relapse is fivefold more likely, adversely affecting health, employment, and social functioning. The Spanish Adherencia Terapéutica en la Esquizofrenia (ADHES) survey was developed to determine the scope and causes of medication nonadherence in schizophrenia.

Methods: The 20-question ADHES survey was distributed to 19,370 psychiatrists in 13 Asia-Pacific countries in January-April 2012, to ascertain psychiatrists' perceptions of antipsychotic medication adherence levels among their schizophrenia patients, reasons for partial/nonadherence, their preferred methods of assessing adherence, and strategies to improve adherence. Responses are reported as mean and range across countries.

Results: Four thousand, six hundred sixty one psychiatrists (24\% of recipients) completed the survey (highest contributors: People's Republic of China, 1854; India, 1616). Psychiatrists perceived that $56 \%$ (range, 30\%-71\%) of schizophrenia patients were non- or partially adherent to medication. Patients discontinue medication primarily due to lack of insight into their condition (mean, 37\%; 1\%-65\%) and because patients consider medication unnecessary when feeling better (mean, 27\%; 15\%-68\%). Over half of psychiatrists (mean, 55\%; 42\%-99\%) assess medication adherence at every visit, almost exclusively $(81 \%)$ by asking their patients, versus quantitative measures. One in three psychiatrists expressed their preference to switch to or add a long-acting antipsychotic to improve adherence (15\%-82\%).

Conclusions: The substantial prevalence of partial/nonadherence to medication demonstrates that more proactive management of patients with schizophrenia is needed to improve adherence and thereby treatment outcomes.

Registration: Registration of this study was not required.

Keywords: schizophrenia, antipsychotic, APAC, survey, adherence

\section{Background}

Nonadherence to antipsychotic medication is one of the major challenges for clinicians treating patients with schizophrenia, ${ }^{1}$ and on the order of exercise or weight reduction with regard to trouble in achieving adherence adequate enough to advance beneficial effects. ${ }^{2}$ The prevalence of medication nonadherence in schizophrenia is consistent with that of other chronic illnesses (eg, hypertension, asthma). ${ }^{3}$

In a review of 39 studies published between 1981 and 2002, Lacro et al noted medication nonadherence rates ranging from $4 \%$ to $72 \%$ (median, $40 \%$ ) among patients with schizophrenia, depending on how adherence was defined and measured, the patient population studied (eg, stable vs recently hospitalized outpatients), and the duration and type of evaluation (eg, retrospective, cross-sectional, observational). ${ }^{4}$ The 3-year prospective, 
observational Worldwide-Schizophrenia Outpatient Health Outcomes (W-SOHO) trial and the National Institute of Mental Health-sponsored Clinical Antipsychotic Trials of Intervention Effectiveness (CATIE) trial provide further evidence of how nonadherence can play out in clinical practice. At the baseline of the W-SOHO study, which recruited 17,384 schizophrenia patients from 37 countries (regions: East Asia, $\mathrm{n}=1,223$; Europe, $\mathrm{n}=12,254$; Latin America, $\mathrm{n}=2,566$; North Africa/Middle East, $\mathrm{n}=1,341$ ), $15 \%$ of investigators cited incomplete medication adherence as the reason for initiating or changing medication at study entry (range, $10 \%$ in East Asia to $21 \%$ in Latin America). ${ }^{5}$ In the sentinel CATIE trial of patients with chronic schizophrenia, the majority discontinued their assigned antipsychotic agent (a surrogate measure of nonadherence): In Phase I of the study, $74 \%$ of 1,460 patients discontinued before completing the 18 months of assigned treatment with an antipsychotic agent. $^{6}$ In Phase II of CATIE, 69\% of 90 patients (efficacy pathway) and $74 \%$ of 333 patients (tolerability pathway) discontinued treatment before completion of the study; median treatment duration was 4 and 5 months in the respective pathways. ${ }^{7,8}$ Taken together, these findings underscore how challenging it is for schizophrenia patients to remain on antipsychotic treatment over a sustained period of time.

The implications of nonadherence for schizophrenia management are far-reaching. ${ }^{9}$ Partial/nonadherence to medication has a major impact on the course of illness and treatment outcomes, resulting in persistence of symptoms, approximately fivefold increased risk of relapse (as compared with patients who continue taking their medication), occupational and social dysfunction, increased rate and duration of hospitalization, and increased risk of attempted suicide. ${ }^{10-13}$ In addition, relapse begets relapse, with illness becoming resistant to treatment and previous gains increasingly more difficult to achieve. ${ }^{14,15}$ Nonadherence to medication also impacts cost of care, increasing outpatient service costs for schizophrenia by almost threefold. ${ }^{16}$

The Spanish Adherencia Terapéutica en la Esquizofrenia (ADHES) program (translated as: therapeutic adherence in schizophrenia) commenced in 2003, aimed at raising awareness of the problem of partial/nonadherence to medication in the treatment of mental illness. As a component of the ADHES program, a survey was developed and first conducted in Spain, ${ }^{17}$ and then in the whole of Europe, the Middle East, and Africa (EMEA), ${ }^{18}$ appraising psychiatrists' opinions about the scope and causes of partial or nonadherence to antipsychotic agents among their schizophrenia patients. Using the ADHES survey, the objectives of the study reported here were to determine perceptions of Asia-Pacific (APAC) psychiatrists regarding antipsychotic medication adherence levels among their schizophrenia patients, reasons for their patients' partial/nonadherence, and their preferred methods of assessing adherence.

\section{Methods}

The ADHES survey has been described in detail elsewhere. ${ }^{17}$ In brief, the ADHES survey consists of 20 questions relating to the demographic characteristics and practice settings of participating psychiatrists and to their perceptions of different factors that affect schizophrenia patients' partial/ nonadherence to antipsychotic medication. The original survey was translated from Spanish to English and then from English into local languages; the survey was then checked for accuracy by native speakers and by back-translation to English before being administered in APAC.

Surveys were handed out at a national conference in India (January 2012) at which the majority of Indian psychiatrists were in attendance. In all other APAC countries, extensive lists of psychiatrists by country were used to disseminate the survey widely during January-April 2012, either by mail (Australia) or via Janssen-Cilag representatives. Psychiatrists received the ADHES survey in a package that also contained a prepaid envelope and a letter explaining the objectives of the survey.

\section{Data collection and analysis}

Respondents completed the survey under anonymity; patientspecific information was not collected. No effort was made to follow-up with nonresponding survey recipients. A research agency (Millward Brown, Warwick, UK) summarized survey response data descriptively. Statistical testing was not performed.

In recording their responses, psychiatrists indicated the adherence status of the schizophrenia patients they had seen in the preceding month, by estimating the percentage of patients in each of the following categories: adherent (took $\geq 90 \%$ of prescribed doses), partially adherent (took $\geq 30$ to $<90 \%$ of prescribed doses), or nonadherent (took $<30 \%$ of prescribed doses). ${ }^{18}$ The arithmetic mean of the values entered for each of the above categories (ie, percentages of patients who were adherent, partially adherent, or nonadherent to treatment) was calculated based on all respondents who answered the question.

Regarding patients' views and behaviors contributing to partial or nonadherence, psychiatrists were instructed to estimate some responses based on the percentage of patients 
falling into each of three groupings (ie, $<20 \%, 20 \%-50 \%$, and $>50 \%$ of patients). The mean percent of patients was predefined as: $<20 \%$ of patients, mean score value $=10 \%$; between $20 \%$ and $50 \%$ of patients, mean score value $=35 \%$; and, $>50 \%$ of patients, mean score value $=75 \%$.

For all questions except those assessing adherence (as noted above), the raw data were converted to percentages that were based on all respondents who were asked the question. If there was no response to the question then that respondent was included in the base, but defaulted into the 'not answered' category. The data were not weighted.

\section{Results}

The ADHES survey was distributed to 19,370 psychiatrists across 13 countries in the APAC region. A total of 4,661 (24\%) psychiatrists completed the survey. The highest number of respondents practiced in the People's Republic of China and India. The countries in which respondents were in practice (and number of respondents, in decreasing order) were: People's Republic of China (1,854), India $(1,616)$, Australia (406), Taiwan (195), Vietnam (107), New Zealand (99), Indonesia (97), Hong Kong (77), Philippines (71), Thailand (68), Singapore (42), Malaysia (17), and Korea (12). The respondents were $60 \%$ male; $15 \%$ aged $\leq 30$ years, $60 \%$ aged $31-50$ years, $16 \%$ aged $51-60$ years, and $7 \%$ aged $\geq 61$ years ( $2 \%$ data missing); and, $76 \%$ in clinical (vs academic) practice (Table 1). Over half (58\%) treat their patients, at least in part, in an inpatient setting.

APAC psychiatrists estimated that $56 \%$ of patients with schizophrenia are partially or nonadherent with their antipsychotic medication (Figure 1), with variations seen within APAC (lowest partial/nonadherence in Vietnam [30\%], Australia, and Thailand [each 51\%], and highest in Singapore and Malaysia [each 71\%]).

Psychiatrists opined that their schizophrenia patients discontinue antipsychotic medication primarily due to lack of insight into their condition (mean across APAC, 37\%; highest in Hong Kong [64\%] and Taiwan [65\%]) and because patients consider medication unnecessary when feeling better (mean across APAC, 27\%; highest in Indonesia [68\%] and Vietnam [65\%]) (Figure 2). Other less common reasons for discontinuation, with substantial variability across APAC countries, were cognitive impairment (highest in the Philippines [24\%], India [13\%], and the People's Republic of China [12\%]) and undesirable side effects (highest in Australia [29\%]).

According to the ADHES survey respondents, only a minority $(32 \%)$ of patients are able to attribute clinical deterioration to medication nonadherence (lowest in Vietnam
Table I Summary of survey respondents $(n=4,66$ I)

\begin{tabular}{|c|c|}
\hline \multicolumn{2}{|l|}{ Sex, n (\%) ${ }^{\mathrm{a}}$} \\
\hline Male & $2,805(60)$ \\
\hline Female & $\mathrm{I}, 733(37)$ \\
\hline \multicolumn{2}{|l|}{ Age, years ${ }^{\mathrm{a}}$} \\
\hline Mean (SD) & $43(11.35)$ \\
\hline Range & $21-70+$ \\
\hline \multicolumn{2}{|l|}{ Age distribution, $\mathrm{n}(\%)$} \\
\hline $21-30$ years & $676(15)$ \\
\hline $31-40$ years & $\mathrm{I}, 428(3 \mathrm{I})$ \\
\hline $4 I-50$ years & I,360 (29) \\
\hline $5 \mathrm{I}-60$ years & $767(16)$ \\
\hline $6 \mathrm{I}-70$ years & $260(6)$ \\
\hline Over 70 years & $53(I)$ \\
\hline \multicolumn{2}{|l|}{ Professional role, $\mathrm{n}(\%)^{\mathrm{b}, \mathrm{c}}$} \\
\hline Academic & $84 \mid(18)$ \\
\hline Clinical & $3,557(76)$ \\
\hline \multicolumn{2}{|l|}{ Practice setting, $n(\%)^{c, d}$} \\
\hline Tertiary/referral & $950(20)$ \\
\hline Private setting & $829(18)$ \\
\hline Hospital-based & $2,703(58)$ \\
\hline Psychiatric outpatient department & $\mathrm{I}, 007(22)$ \\
\hline
\end{tabular}

Notes: ${ }^{\mathrm{a}}$ Three percent of respondents to the survey did not provide this information; bfourteen percent of respondents to the survey did not provide this information; 'respondents could select all that applied; deleven percent of respondents to the survey did not provide this information.

Abbreviation: SD, standard deviation.

[14\%] and Korea [18\%] and highest in Indonesia [41\%]). In the caregivers' view, fewer than 4 in 10 patients $(37 \%)$ understand there is a risk of relapse if they do not take their medication regularly (lowest in Vietnam [18\%] and highest in Australia [42\%], Taiwan [48\%], and Korea [55\%]).

Across APAC, over half of psychiatrists (mean of 55\%; lowest in India [42\%] and highest $[\geq 87 \%]$ in Indonesia, Hong Kong, Malaysia, and Vietnam) reported that they assess medication adherence at every visit (Figure 3). The majority of psychiatrists assess adherence almost exclusively by asking their patients $(81 \%)$ or a close informant $(86 \%)$, versus using objective measures (Figure 4), which are used most often in Thailand (75\% count pills), Hong Kong, Taiwan, Australia (drug plasma levels measured in 73\%, 69\%, and $65 \%$, respectively), and the People's Republic of China (63\% use logbook and $18 \%$ use adherence scale).

Psychiatrists reported that $42 \%$ of their patients, on average, need reminding by family members/carers to take their medication as prescribed (range, 36\%-37\% in Singapore and India to $55 \%-58 \%$ in Taiwan, Indonesia, Thailand, and Hong Kong). Fewer of their patients (36\%; range, 30\%-31\% in Singapore and India, to $48 \%-59 \%$ in Malaysia and Korea) rely on a nurse, psychiatrist, or professional carer to do so.

The strategies considered to manage nonadherence reflect a change or simplification in the current treatment regimen. 


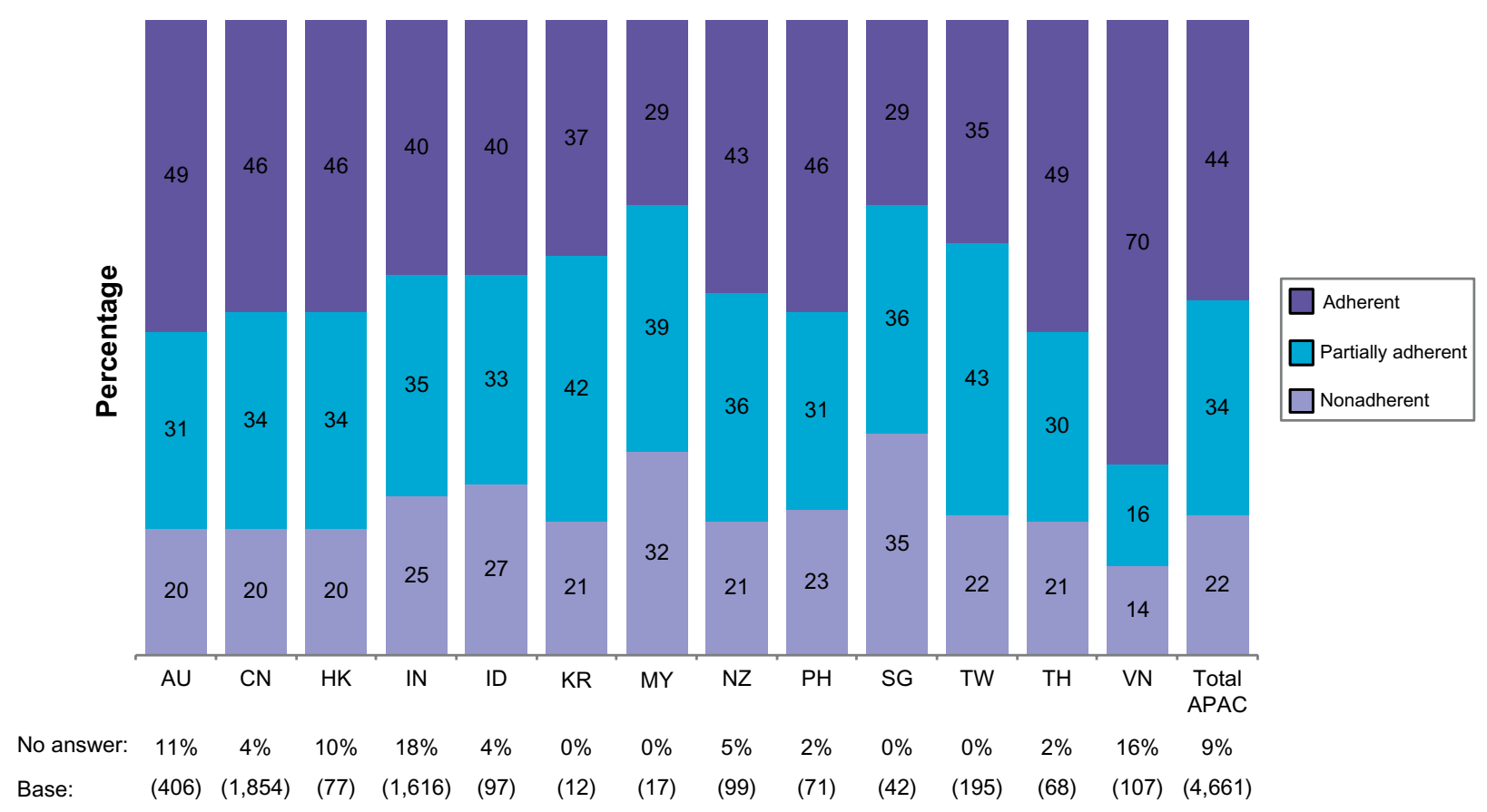

Figure I Proportion of schizophrenia patients perceived to be partially or nonadherent to their antipsychotic medication.*

Notes: *Of the patients with schizophrenia you saw in the past month, what percentage do you suspect may have been nonadherent, partially adherent, or fully adherent? Nonadherent was defined as $<30 \%$ of prescribed doses taken; partially adherent was defined as $\geq 30 \%-<90 \%$ of prescribed doses taken; and adherent was defined as $\geq 90 \%$ of prescribed doses taken.

Abbreviations: AU, Australia; CN, People's Republic of China; HK, Hong Kong; IN, India; ID, Indonesia; KR, Korea; MY, Malaysia; NZ, New Zealand; PH, Philippines; SG, Singapore; TW, Taiwan; TH, Thailand; VN, Vietnam; APAC, Asia-Pacific.

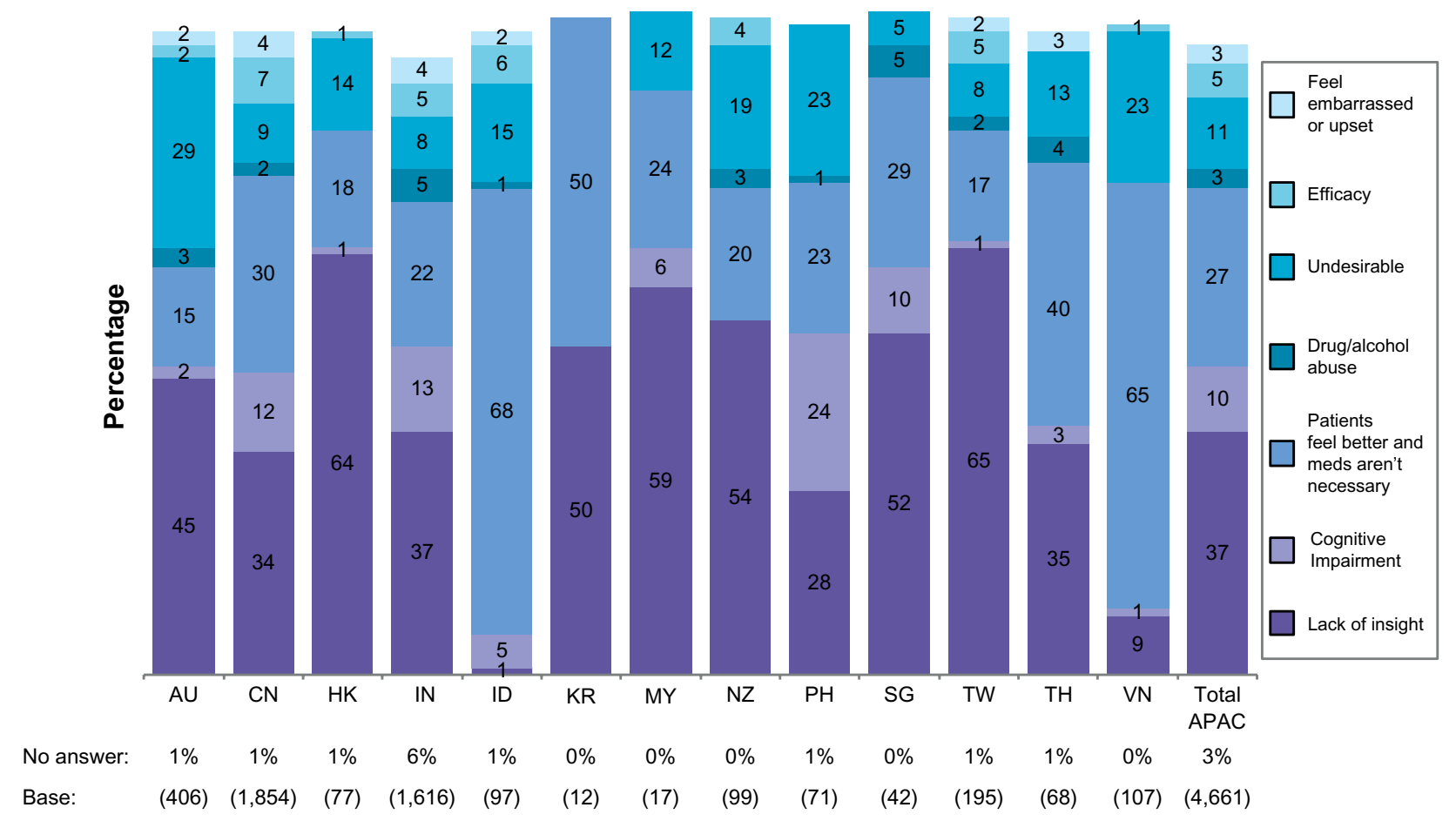

Figure 2 Psychiatrists' views on the most important reason for their schizophrenia patients discontinuing antipsychotic medication.*

Notes: *What is, in your experience, the most important reason for your patients to discontinue medication? Responses do not always add to I00\% as 'no answers' are not presented in the stacked bars.

Abbreviations: AU, Australia; CN, People's Republic of China; HK, Hong Kong; IN, India; ID, Indonesia; KR, Korea; MY, Malaysia; NZ, New Zealand; PH, Philippines; SG, Singapore; TW, Taiwan; TH, Thailand; VN, Vietnam; APAC, Asia-Pacific. 


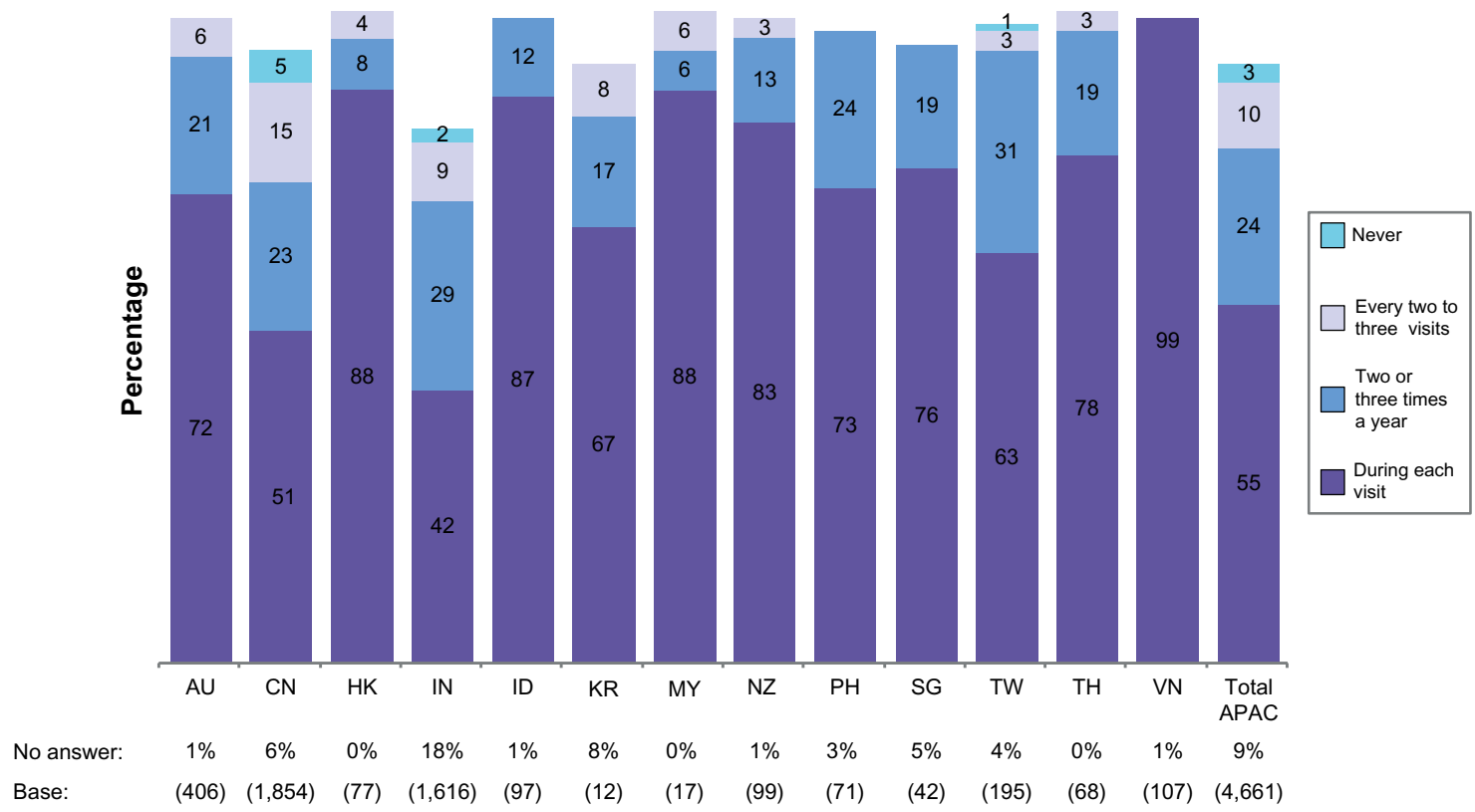

Figure 3 Psychiatrists' views on the frequency with which they assess adherence in their patients.*

Notes: *How often do you assess adherence in your patients? Responses do not always add to $100 \%$ as 'no answers' are not presented in the stacked bars.

Abbreviations: AU, Australia; CN, People's Republic of China; HK, Hong Kong; IN, India; ID, Indonesia; KR, Korea; MY, Malaysia; NZ, New Zealand; PH, Philippines; SG, Singapore; TW, Taiwan; TH, Thailand; VN, Vietnam; APAC, Asia-Pacific.

Among all treatment modifications considered, one-third of APAC psychiatrists (lowest in Vietnam [15\%] and India [24\%] and highest [51\%-82\%] in Indonesia, New Zealand, Thailand, Taiwan, and Malaysia) favor switching to or adding a long-acting antipsychotic as their preferred treatment option for addressing adherence problems (Figure 5).

\section{Discussion}

The ADHES schizophrenia survey was conducted in APAC to gain insights into the perceptions of psychiatrists in the region regarding the scope and causes of antipsychotic medication nonadherence among their schizophrenia patients as well as the methods of assessing adherence, and preferred

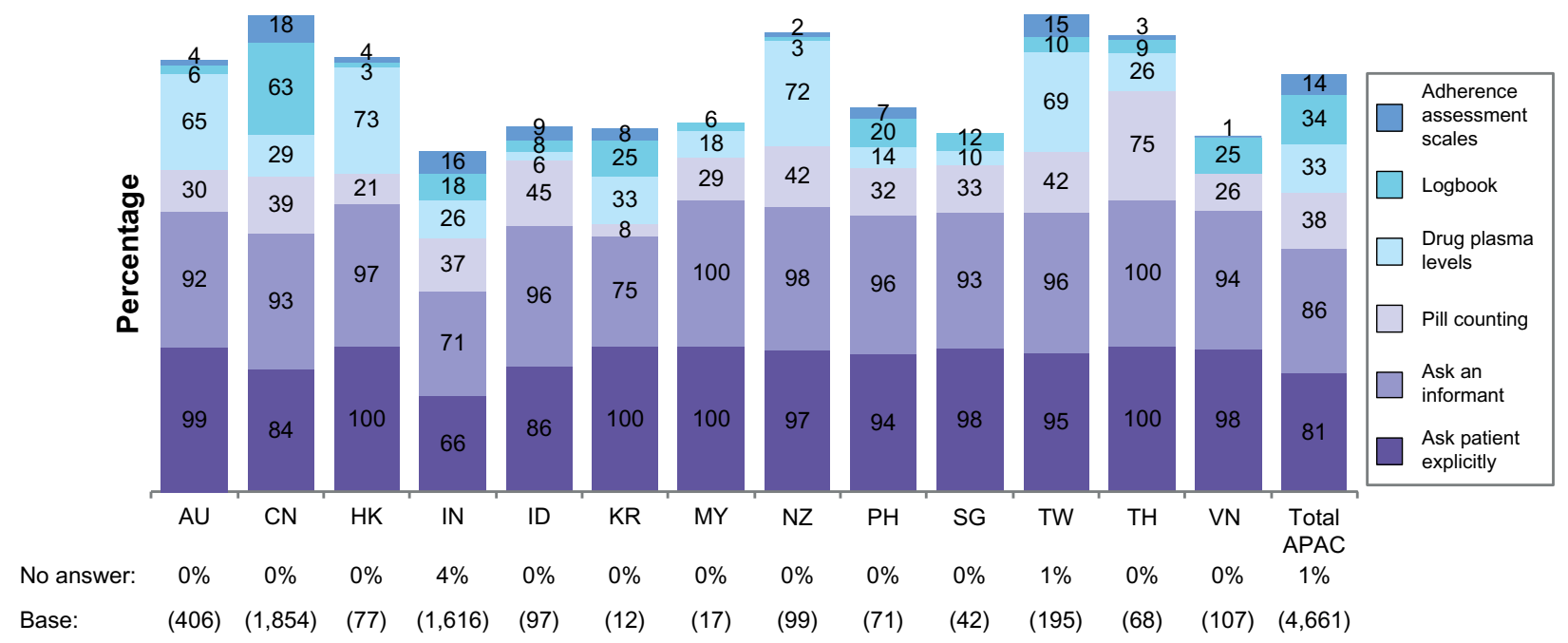

Figure 4 Psychiatrists' views on the approaches they use to assess adherence.*

Notes: *During your consultations, which approach do you normally use to assess adherence? Please select the approach you use most as well as all approaches you use. Responses do not add to $100 \%$ as multiple answers were allowed.

Abbreviations: AU, Australia; CN, People's Republic of China; HK, Hong Kong; IN, India; ID, Indonesia; KR, Korea; MY, Malaysia; NZ, New Zealand; PH, Philippines; SG, Singapore; TW, Taiwan; TH, Thailand; VN, Vietnam; APAC, Asia-Pacific. 


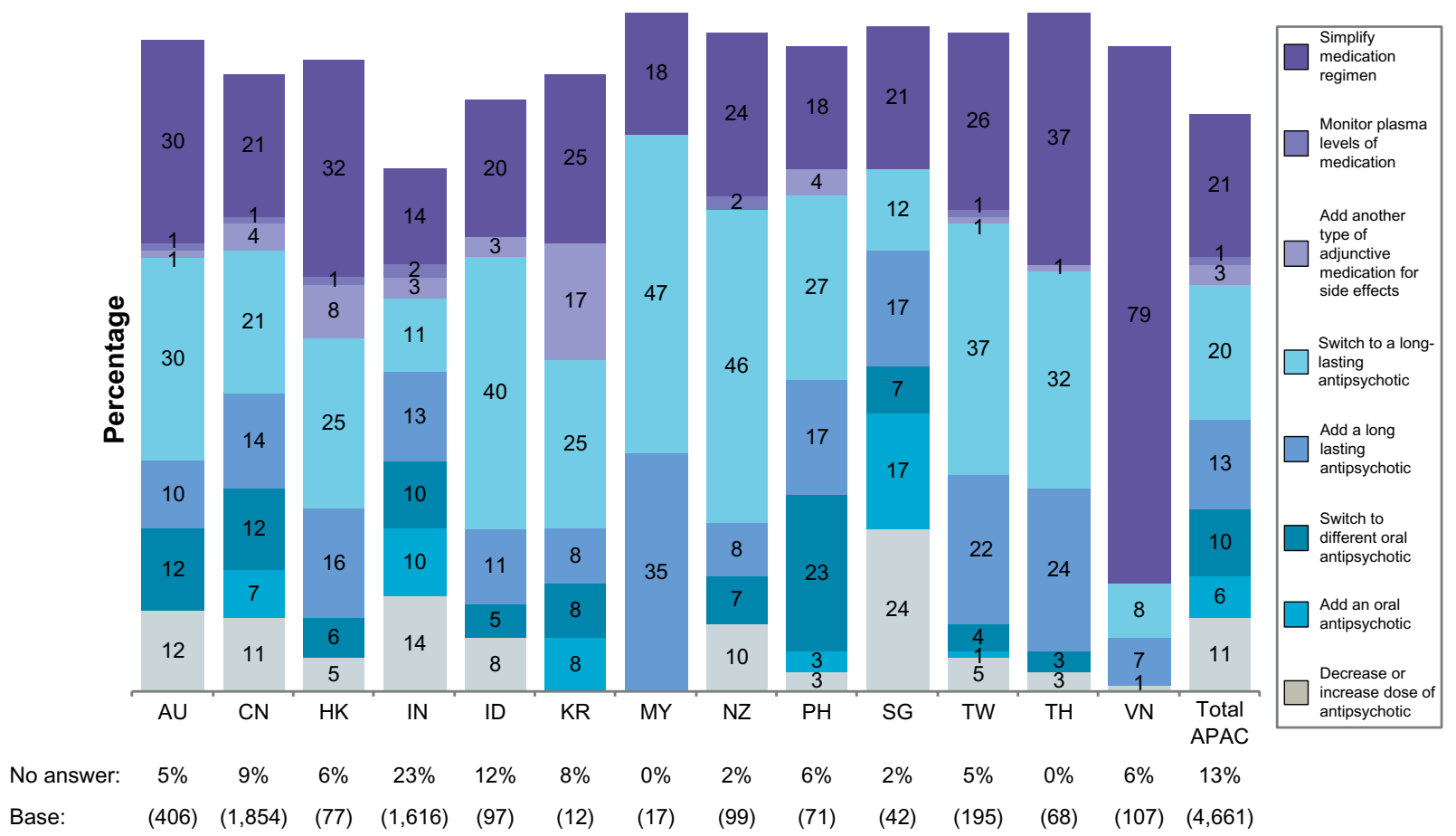

Figure 5 APAC psychiatrists' views on the preferred pharmacological approach they use to address an adherence problem in their patients.*

Notes: *Please indicate which one of the following pharmacological strategies you would preferentially use to address an adherence problem in your patients with schizophrenia. Responses do not always add to $100 \%$ as 'no answers' are not presented in the stacked bars.

Abbreviations: AU, Australia; CN, People's Republic of China; HK, Hong Kong; IN, India; ID, Indonesia; KR, Korea; MY, Malaysia; NZ, New Zealand; PH, Philippines; SG, Singapore; TW, Taiwan; TH, Thailand; VN, Vietnam; APAC, Asia-Pacific.

strategies to improve adherence. By using a survey administered in the EMEA previously, similarities and differences not only among APAC countries, but also between APAC and EMEA can be identified, thereby promoting a crosscultural understanding of antipsychotic nonadherence in schizophrenia.

We report on a large study sample of 4,661 psychiatrists practicing in 13 countries within the APAC region. The ADHES response rate of $24 \%$ in the APAC was twofold higher than that in the EMEA (12\%). ${ }^{18}$ Although eight of the APAC countries had fewer than 100 respondents each, they were generally well represented in the survey, as reflected by the proportion that respondents comprised to the total number of practicing psychiatrists per country (eg, Singapore [31\%], Hong Kong [25\%], New Zealand [24\%], Thailand [23\%], and Philippines [20\%]). ${ }^{19}$

APAC psychiatrists considered that over half (56\%) of patients with schizophrenia are partially or nonadherent with their antipsychotic medication. Based on prevalence figures from the World Health Organization, ${ }^{20}$ this represents approximately 7.9 million affected patients. Overall, similar levels of adherence were reported by psychiatrists across APAC and EMEA, where $53 \%$ of patients were reported partially or nonadherent. ${ }^{18}$ Within APAC, the lowest rate of nonadherence was reported in Vietnam (30\%), which may not be representative of the other countries. Most Vietnamese survey respondents $(88 \%)$ reported following and treating schizophrenia patients in a hospital, where they can achieve good adherence. Their view on adherence among other patients is limited by the fact that these patients are managed by local mental health care centers, therefore the original treating physicians are not able to monitor and follow-up on their patient's treatment.

APAC psychiatrists cited a lack of insight as the main reason for patient partial/nonadherence, a perspective similarly held by EMEA psychiatrists. To the extent that lack of insight is static, trait-like, and unmodifiable by patient education, it follows that cooperation may need to be bypassed, for instance with long-acting injectable antipsychotics. Cognitive impairment was a more common reason for nonadherence in APAC than reported in EMEA. In the opinion of ADHES survey respondents, a minority of schizophrenia patients in APAC (32\%) and EMEA $\left(32 \%{ }^{21}\right)$ relate clinical deterioration to antipsychotic nonadherence.

APAC psychiatrists noted that approximately a third of their patients need help from caregivers (family member or professional), placing a burden on them to help patients adhere to their treatment plan. The perceived caregiver burden 
in APAC was lower than that reported in the EMEA ${ }^{18}$ ), due in large part to low rates of caregiver burden reported by respondents from India. In APAC countries, more so than in EMEA and other developed regions, schizophrenia patients tend to live with and are supported by an extended family system (rather than in residential facilities), due not only to cultural influences, but also the relative lack of a social welfare system for such patients. ${ }^{22}$

Our observations confirm those of others who implicate patients' lack of insight as the most important among factors associated with poor medication adherence in schizophrenia patients. ${ }^{4,13}$ Forming the basis for 2009 Consensus Practice Guidelines ${ }^{13}$ for assessing and improving adherence, 41 leading experts in schizophrenia management completed a survey in which they answered questions about the definition and extent of nonadherence, risk factors and assessment methods for nonadherence, and interventions for specific nonadherence problems. The experts ranked the following factors (in descending order of importance) as potential contributors to adherence problems in schizophrenia: poor insight into having an illness; distress associated with persistent side effects (or fear of potential side effects); lack of/partial efficacy with continued symptoms; belief that medications are no longer needed; ongoing substance use problems; cognitive deficits; lack of social support to help with medication-taking; practical problems (eg, transportation, financial); difficulty building therapeutic alliance (with health care providers, caregivers); lack of daily routines; complexity of treatment regimen; significant others ambivalent/opposed to medication; stigma associated with mental illness and medication; and, negative attitudes towards medications in general.

Compared with their EMEA counterparts (76\%), APAC psychiatrists assess adherence levels less frequently, with $55 \%$ doing so regularly or during every visit. The lowest adherence assessment frequency was reported in the People's Republic of China (51\%) and India (42\%). Furthermore, APAC psychiatrists reported assessing medication adherence with objective measures less often than EMEA psychiatrists who had previously responded to the ADHES survey. ${ }^{18}$ Basing adherence on patient interview can be especially unreliable in countries where patients have negative beliefs about psychiatric conditions or embarrassment about taking antipsychotic medication (Figure 2).

One out of every three APAC psychiatrists favor switching to or adding a long-acting antipsychotic as their preferred treatment option for addressing adherence problems, compared to three out of every five (62\%) EMEA survey respondents. ${ }^{18}$ Treatment of schizophrenia patients with a long-acting injectable antipsychotic (vs oral) agent has been shown to decrease relapse and hospitalization rates in many, but not all, studies. ${ }^{23,24}$ The preference of Australian psychiatrists for a long-acting agent (40\%), as well as their responses to other questions (eg, higher perceived adherence level, undesirable side effects as a key driver for nonadherence) indicates that they are more aligned with psychiatrists in the EMEA than other APAC countries. This may be a reflection of similarities in its health care system, earlier introduction of long-acting antipsychotic agents, and community-based treatment programs.

Our findings on the prevalence of antipsychotic nonadherence are limited by the fact that its assessment by physicians' clinical judgment oftentimes results in underestimated rates, as compared with an objective tool. ${ }^{25}$ A single method for identifying survey respondents was not utilized: some received the survey by mail and others either during a conference or from a representative of the survey's sponsor. Thus, a social desirability bias cannot be ruled out. Furthermore, it is unknown whether the survey sample is representative of all psychiatrists in APAC and whether their responses to the ADHES reflect those of the broad population of their colleagues in the region. Nevertheless, comparisons among APAC countries or between APAC and EMEA on the same survey items remain of interest.

In summary, the substantial prevalence of partial/ nonadherence to antipsychotic medication in APAC, as reported by psychiatrists practicing in the region, demonstrates that more proactive management of patients with schizophrenia is needed to improve adherence and thereby treatment outcomes. To further our findings, future trials could examine other factors affecting adherence (eg, cognitive impairment, disease severity, motivational deficits, stigma, environmental stressors, lack of social support, substance abuse, cultural and religious beliefs, treatmentrelated side effects, poor therapeutic alliance, access to treatment, cost of medication) and other measures of adherence (eg, prolactin). We also propose longitudinal, multi-country study of patients' beliefs, as compared to those of their health care providers.

\section{Contributions}

JMO conceived the original ADHES survey. JMO, MT, JK, MYZ, HYZ, and FZ were members of this study's Steering Committee, which ratified the survey and designed the conduction of the study. All authors had full access to the data, contributed to data interpretation and the development of the 
manuscript, and read and approved the final manuscript in accordance with ICMJE criteria.

\section{Acknowledgments}

Sandra Norris, Pharm.D. provided writing assistance and Wendy P Battisti, Ph.D. (Janssen Research and Development, LLC) provided additional editorial assistance. The authors thank the survey respondents for their contributions to this data.

\section{Disclosure}

Funded by Janssen Asia Pacific, a division of Johnson and Johnson Pte. Ltd, Singapore. Registration of this study was not required. Dr Fan Zhang is an employee of Xian Janssen Pharmaceutical, Beijing, People's Republic of China. Other authors report no conflicts of interest.

\section{References}

1. Kane JM. Review of treatments that can ameliorate nonadherence in patients with schizophrenia. J Clin Psychiatry. 2006;67(Suppl 5):9-14.

2. Keith SJ, Kane JM. Partial compliance and patient consequences in schizophrenia: our patients can do better. J Clin Psychiatry. 2003;64(11): 1308-1315.

3. Llorca PM. Partial compliance in schizophrenia and the impact on patient outcomes. Psychiatr Res. 2008;161(2):235-247.

4. Lacro JP, Dunn LB, Dolder CR, Leckband SG, Jeste DV. Prevalence of and risk factors for medication nonadherence in patients with schizophrenia: a comprehensive review of recent literature. J Clin Psychiatry. 2002;63(10):892-909.

5. Karagianis J, Novick D, Pecenak J, et al. Worldwide-Schizophrenia Outpatient Health Outcomes (W-SOHO): baseline characteristics of pan-regional observational data from more than 17,000 patients. Int J Clin Pract. 2009;63(11):1578-1588.

6. Lieberman JA, Stroup TS, McEvoy JP, et al; Clinical Antipsychotic Trials of Intervention Effectiveness (CATIE) Investigators. Effectiveness of antipsychotic drugs in patients with chronic schizophrenia. $N$ Engl J Med. 2005;353(12):1209-1223.

7. Stroup TS, Lieberman JA, McEvoy JP, et al; CATIE Investigators. Effectiveness of olanzapine, quetiapine, risperidone, and ziprasidone in patients with chronic schizophrenia following discontinuation of a previous atypical antipsychotic. Am J Psychiatry. 2006;163(4):611-622.

8. McEvoy JP, Lieberman JA, Stroup TS, et al; CATIE Investigators. Effectiveness of clozapine versus olanzapine, quetiapine, and risperidone in patients with chronic schizophrenia who did not respond to prior atypical antipsychotic treatment. Am J Psychiatry. 2006;163(4):600-610.

9. Masand PS, Roca M, Turner MS, Kane JM. Partial adherence to antipsychotic medication impacts the course of illness in patients with schizophrenia: a review. Prim Care Companion J Clin Psychiatry. 2009;11(4):147-154.
10. McEvoy JP, Howe AC, Hogarty GE. Differences in the nature of relapse and subsequent inpatient course between medication-compliant and noncompliant schizophrenic patients. J Nerv Ment Dis. 1984;172(7): 412-416.

11. Novick D, Haro JM, Suarez D, Perez V, Dittmann RW, Haddad PM. Predictors and clinical consequences of non-adherence with antipsychotic medication in the outpatient treatment of schizophrenia. Psychiatry Res. 2010;176(2-3):109-113.

12. Robinson D, Woerner MG, Alvir JM, et al. Predictors of relapse following response from a first episode of schizophrenia or schizoaffective disorder. Arch Gen Psychiatry. 1999;56(3):241-247.

13. Velligan DI, Weiden PJ, Sajatovic M, et al; for Expert Consensus Panel on Adherence Problems in Serious and Persistent Mental Illness Collaborators. The expert consensus guideline series: adherence problems in patients with serious and persistent mental illness. J Clin Psychiatry. 2009;70(Suppl 4):1-46.

14. Kane JM. Treatment adherence and long-term outcomes. CNS Spectrums. 2007;12(10 Suppl 17):21-26.

15. Lieberman JA, Koreen AR, Chakos M, et al. Factors influencing treatment response and outcome of first-episode schizophrenia: implications for understanding the pathophysiology of schizophrenia. J Clin Psychiatry. 1996;57(Suppl 9):5-9.

16. Knapp M, King D, Pugner K, Lapuerta P. Non-adherence to antipsychotic medication regimens: associations with resource use and costs. Br J Psychiatry. 2004;184:509-516.

17. Giner J, Cañas F, Olivares JM, et al. Treatment adherence in schizophrenia. A comparison between patient's, relative's and psychiatrist's opinions. [Article in Spanish]. Actas Esp Psiquiatr. 2006;34(6):386-392.

18. Olivares JM, Alptekin K, Azorin JM, et al. Psychiatrists' awareness of adherence to antipsychotic medication in patients with schizophrenia: results from a survey conducted across Europe, the Middle East and Africa. Patient Prefer Adherence. 2013;7:121-132.

19. World Health Organization. Mental Health Atlas-2011 country profiles. Available at: http://www.who.int/mental_health/evidence/atlas/profiles/ en/index.html. Accessed June 19, 2013.

20. World Health Organization. The global burden of disease: 2004 update. Geneva, Switzerland: World Health Organization; 2004:32.

21. Naber D, Alptekin K, Azorin JM, et al. The EMEA ADHES survey in schizophrenia: psychiatrists' perceptions of the extent of assessment and management of partial and non-adherence to medication [P03-277]. Eur Psychiatry. 2011;26(S1):1446.

22. Razali SM. Prevention of relapse and interventions for enhancing medication adherence in schizophrenia: An East Asian perspective. Asia-Pacific Psychiatry. 2010;2(2):68-76.

23. Olivares JM, Rodriguez-Morales A, Diels J, et al. Long-term outcomes in patients with schizophrenia treated with risperidone long-acting injection or oral antipsychotics in Spain: Results from the electronic Schizophrenia Treatment Adherence Registry (e-STAR). Eur Psychiatry. 2009;24(5):287-296.

24. Zhornitsky S, Stip E. Oral versus long-acting injectable antipsychotics in the treatment of schizophrenia and special populations at risk for treatment nonadherence: a systematic review. Schizophr Res Treatment. 2012;2012:407171. Epub February 15, 2012.

25. Byerly M, Fisher R, Whatley K, et al. A comparison of electronic monitoring vs clinician rating of antipsychotic adherence in outpatients with schizophrenia. Psychiatry Res. 2005;133(2-3):129-133.
Neuropsychiatric Disease and Treatment

\section{Publish your work in this journal}

Neuropsychiatric Disease and Treatment is an international, peerreviewed journal of clinical therapeutics and pharmacology focusing on concise rapid reporting of clinical or pre-clinical studies on a range of neuropsychiatric and neurological disorders. This journal is indexed on PubMed Central, the 'PsycINFO' database and CAS.

\section{Dovepress}

The manuscript management system is completely online and includes a very quick and fair peer-review system, which is all easy to use. Visit http://www.dovepress.com/testimonials.php to read real quotes from published authors. 